\title{
Los origenes de la Campaña del Rif de 1909
}

Francisco Saro Gandarillas Ilistoriador

A estas alturas del tiempo, casi finalizado el siglo XX. no creemos que nadie medianamente avisado sobre la historia norteafricana ignore o desdeñe la significativa, o mejor aún decisiva, influencia que las campañas llevadas a cabo por fuerzas militares españolas durante el primer tercio de siglo en el vecino territorio marroquí han tenido en la ciudad de Melilla. Influencia capital que un comprensible aunque injustificado pudor ha tenido velada hasta no hace mucho tiempo. Pudor comprensible puesto que a nadie con sensibilidad le parecerá un progreso brillante el medrar amparándose en las necesidades que deben satisfacer las costosas operaciones militares, con los anexos de destrucción y sufrimientos que inevitablemente llevan consigo los conflictos bélicos. Injustificado porque si nos remontamos suficientemente en el tiempo será sin duda muy difícil encontrar algún territorio, comarca, pueblo o ciudad que no se haya favorecido en algún momento de su pequeña historia por la presencia en sus cercanías de contingentes armados, empleados en hechos militares de cualquier índole o razón. $O$ perjudicado, pues está claro que en estas polémicas además de ganadores hay perdedores, y con bastante frecuencia. sólo perdedores.

La campaña iniciada por España en la zona marroquí cercana a Melilla en 1909, también conocida como Campaña del Rif con muy inapropiada denominación, pues los hechos se desarrollaron sobre un territorio que no está incluido en el Rif tradicional, aunque muchos de sus actuales habitantes, por orgullo fácil de entender, se denominan a sí mismos rifeños; la campaña, insistimos, es un ejemplo muy apropiado para estudiar la 
influencia que las guerras al estilo imperante en aquella época ejercían sobre los territorios tomados como base, siendo Melilla, por razones obvias, puerto $y$ base de todas las operaciones llevadas a cabo por España en el Rif oriental entre 1909 y 1927, año este último en que se da término a las campañas con carácter oficial, finalización que, a su vez, tuvo importante influencia en la ciudad y cuyo estudio dejamos al buen hacer de quien quiera profundizar en tema tan sugestivo.

Hemos dicho "al estilo imperante en la época" porque evidentemente los sistemas militares actuales, de muy distinta condición a los existentes a principios de siglo, harían que los hechos se desarrollasen hoy, en su malvado supuesto, de muy distinta forma a como lo hicieron en su día los numerosos contingentes aprestados por los gobiernos españoles para la ejecución de la desde mucho tiempo antes anunciada intervención española en el llamado consensuada y eufemísticamente "problema de Marruecos".

Pero, a la inversa de lo que venimos diciendo hasta ahora, bastante menos conocida es la intervención de la ciudad de Melilla como causa originaria inmediata de los sucesos iniciados en 1909, y cuyas consecuencias han dado en un proceso con resultas que en cierto modo se mantienen hasta hoy.

Melilla, "ciudad frontera", como con insistencia la denominaba Salvador Canals (1), y único puerto practicable (2) en el norte africano entre Nemours (Argelia) y Ceuta, estaba "condenada" a ser protagonista de primer papel en los acontecimientos que machaconamente se venían avisando desde principios del siglo XIX, y con iluminadora reiteración durante la segunda mitad del siglo, sobre todo desde que los intereses de Francia, Inglaterra y Alemania y, en menor medida, España, en Marruecos tuvieron el peso suficiente medido en francos, libras, marcos y pesetas, con mayor razón si tenemos en cuenta que entonces el país magrebí era uno de los escasos territorios africanos donde apenas había huellas de la planta del hombre europeo, lo que constituía una preocupante rareza en una época en que se originaban, se nutrían y crecían los grandes colonialismos que en la Historia de la humanidad han sido.

Pero es que además, y este es el punto esencial de este trabajo, no solamente fue Melilla peldaño inevitable en la escalada política, diplomática y militar hacia la intervención, sino que fue origen y primera razón de los hechos acaecidos en julio de 1909 , con mucho mayor propiedad que 
las llamadas "minas del Rif", a quienes se refieren, con insistencia y simplismo poco razonado que llega hasta nuestros días, quienes con mejor o peor fortuna se han ocupado de estos temas, en nuestra opinión sin suficiente justificación que lo avale, como pretendemos hacer ver en las líneas que siguen a continuación.

\section{LOS PRIMJROS PASOS HACIA LA MELILIA MODERNA}

No hace falta tener un profundo conocimiento de la historia de Melilla para saber que hasta 1860 la ciudad -más bien plaza militar- se limitó a cumplir, con diversas alternativas en su función, la doble misión de centinela avanzado sobre el Magreb y, con mucho mejor celo, la de triste y mal reputado presidio, aprovechando para este último cometido su facultad de ser barco anclado en costa tradicionalmente hostil a penetraciones foráneas, por lo que el confinado tenía, en su desventurado destino, dos centinelas en perpetua vigilia, por un lado el ancho mar y por el otro el intratable cabileño cuya vida austera difícilmente podríamos considerarla de mejor calidad que la del propio presidiario. Un lugar, pues, muy a propósito para colocar en él a los rechazados por la sociedad, por sus crímenes comunes; o por los gobiernos, por su oposición al sistema imperante.

Esta circunstancia, que pese a su evidente peligro no impidió que Melilla continuara en manos de España durante cinco siglos; era suficiente para que, salvo en raras ocasiones, apenas se considerara que la plaza pudiera llegar a ser otra cosa que lo que era, si bien no faltaron voces que desde antiguo anhelaran para Melilla otro destino bien distinto, voces que encontraron siempre oídos sordos a su bienintencionada propuesta.

Es con motivo de la campaña de Tetuán de 1859-60 cuando se da un cambio significativo en las expectativas de la ciudad. Una vez más hay que referirse a una guerra para encontrar razones que expliquen nuevos rumbos en el transcurso de la trayectoria urbana melillense.

Una vez ratificado el Tratado de paz con Marruecos el 26 de abril de 1860 , quedaba también ratificado, obligado por las circunstancias, el nonato de 24 de agosto de 1859 por el cual se había llegado a un acuerdo con el Sultán sobre nuevas fronteras para Melilla, invocando a favor de España el reconocimiento y establecimiento de los límites que determinaban la línea de antiguos fuertes defensivos perdidos a finales del siglo XVII. Parece claro que si no hubiese sido impuesto por los hechos de guerra, al 
triunfar la causa española en la dura contienda de Tetuán, el convenio de 1859 jamás hubiese sido hecho efectivo, conociendo, como se conocían, los tradicionales manejos dilatorios que la peculiar política exterior sultaniana tenía acostumbrados.

El nuevo territorio, al fin conseguido tras diversos percances, obligaba necesariamente a su ocupación y vivificación si se quería hacer efectivo y no quedarse en una mera colocación de mojones, y para ello no había más que un camino válido: aumentar la población. Era preciso hacer atractivo el campo de Melilla, cosa nada fácil con los malos informes de que se disponía en aquella época.

De ahí nació la ley de 18 de mayo de 1863 por la que se declaraba puerto franco a este puerto sin puerto, lo mismo que a Ceuta y Chafarinas, beneficio, o supuesto beneficio que se extiende en 1872 al Peñón de Vélez y Alhucemas. Complemento indispensable a esta ley fueron las disposiciones por las que se permitía el acceso a Melilla a todo tipo de población, incluso extranjera, que se dedicara al comercio y, por supuesto, acreditara buena conducta (3).

Algo se consiguió. No lo que se pretendía probablemente, pero bastante si lo comparamos con la situación anterior de marasmo absoluto.

Las cifras de población variaron muy poco durante los treinta años siguientes, pues si en 1863 podía haber unos 400 habitantes además de la guarnición, en 1893 la cifra alcanzaba los 3.031, todavía muy pequeña población para un territorio de 12 kilómetros cuadrados que en el último año seguían sin ocuparse aunque ya se hubiesen hecho tímidos intentos para habitar zonas fuera de las fortificaciones como el barrio del Polígono.

Pero además la población más significativa entre la llegada no era de origen peninsular tal como parecía lo más normal y tal como sin duda se esperaba. Los recién llegados eran sobre todo hebreos procedentes de la zona de Tetuán escapados de las esperadas represalias marroquíes tras la guerra de 1860 por su colaboración con las tropas españolas (4). Precisamente el hecho de que fueran hebreos estos singulares inmigrantes fue causa inmediata para que Melilla tuviera otra faz distinta de la casi exclusiva militar que había tenido hasta entonces. Porque con amparo en la nueva ley de puerto franco, los activos hebreos pusieron en marcha un mecanismo económico hasta entonces inexistente: el comercio de importación y exportación (5). 
No obstante, los inconvenientes propios de una plaza militar actuaron como freno a un desarrollo comercial que sin ellos hubiese sido de mayor amplitud. El estar la plaza en constante estado de guerra con la consiguiente aplicación del temible Código de Justicia Militar para casi todo (6), la falta de un buen puerto, la existencia del antiguo presidio y más tarde del Disciplinario, la inseguridad del territorio dada la escasez de guarnición y, muy importante, la inseguridad jurídica de la propiedad, por un lado entregada a censo y por otro sometida al arbitrio personal del gobernador militar de turno por razones de la defensa; por todas estas razones y algunas más, el desarrollo buscado fue lento aunque sostenido.

El primer resultado de la ley del puerto franco, con su franquicia, fue el hundimiento del pequeño comercio que Francia efectuaba a través de la frontera con Marruecos (7), acaparando Melilla en el transcurso del tiempo todo el comercio desde el Tafilalt, por el valle del Muluya, hasta Uxda y el Dahra.

No todos estaban conformes con el supuesto beneficio del puerto franco. A este respecto las opiniones son muy diversas. Pezzi entendía, por el contrario, que el puerto franco fue un entorpecimiento para el comercio, abundando en razones no demasiado convincentes (8).

En cualquier caso las cifras son elocuentes, y de casi nada se pasó, en 1875, hasta las 1.534 toneladas entre importaciones y exportaciones.

En pesetas, según Morales, y siempre tomando las cantidades con la reserva necesaria por no ser muy fiables, se alcanzaron 1.600 .000 pesetas en $1880, y$ los 3.500 .000 pesetas en 1888, cifras más que respetables (9) pese a su aparente insignificancia.

A finales de los ochenta el comercio de Melilla se iba extendiendo hacia el este y sur marroquí, y en el comienzo de la década siguiente los productos procedentes del mercado melillense alcanzaban y sobrepasaban la zona de Uxda, Beni Mathar y el Dahra por el este, prolongándose hacia el Figuig, y hacia Debdú y Taza hacia el sur y sudoeste. Gabriel Delbrel, en sus recorridos por la zona en los años 1891 y 1892, aseguraba años más tarde que en aquella época gran parte de las mercancías procedían de Melilla (10).

Los franceses se quejaban de que Melilla acaparaba el comercio a la derecha del Muluya, mientras algunos españoles, al contrario, pensaban que era Argelia quien monopolizaba dicho comercio. Así, el que fuera gobernador del Peñón de Vélez entre 1886 y 1889, José Ruiz Cebolli- 
no, destinado en la plaza de Melilla, aseguraba en el Congreso Africanista celebrado entre 1892 y 1893 en Granada que los beneficios del comercio con el Rif se los llevaban los argelinos (11).

Las posibilidades de Melilla como puerto comercial no eran ignoradas totalmente en la península. Su situación era espléndida. "Base de nuestro comercio en el porvenir"; eso sí, sin ignorar que "el avance francés monopolizará el comercio de aquella zona", escribía Luis Andade en 1891 (12), si se le permitía adelantarse sobre la derecha del Muluya como ya pretendían.

\section{AFIANZAMIENTO COMBRGIAL}

El convenio suscrito con Marruecos el 5 de marzo de 1894, por el que se ponía término al conflicto de Melilla conocido como guerra de Margallo, marcó el inicio de unas nuevas relaciones con las kabilas vecinas y aunque no faltaron incidentes que recordaran los viejos tiempos de permanente rivalidad, las relaciones fueron más estrechas hasta el punto de que Melilla vivió una de las épocas de mayor bonanza militar y económica de su historia. La vieja ciudadela era ya "arteria comercial del Rif y kabilas inte-

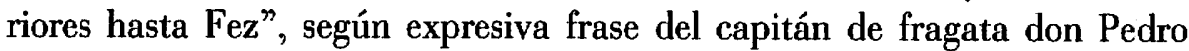
Guarro González, en Melilla antes y durante la campaña de 1893 (13).

Hemos dicho que el final de esta campaña contempló un más que notable aumento de las transacciones comerciales entre Melilla y Marruecos. La suspensión de los intercambios durante las operaciones produjo cierta conmoción entre las kabilas del Nordeste marroquí, ya habituadas a considerar la ciudad española como centro comercial casi exclusivo de la zona. El escaso comercio que aún se derivaba hacia Argelia fue captado por Melilla desde el momento en que los productos entrados por este puerto eran comparativamente mucho más baratos, incluso los de procedencia francesa.

Así lo explica Dechaud: "Nuestros productos, gravados por derechos considerables de aduana, no podían ser entregados al consumo más que con este enorme aumento; ahora bien, estos derechos bastaban para que los marroquíes de Uxda tengan ventaja al comprar en Tánger y, sobre todo, en Melilla" (14).

Dechaud proponía como solución el establecer depósitos francos en la frontera argelomarroquí, e incluso tomaba en consideración la 
opinión de un comerciante de Orán, M’Hammed ben Rahhalen, quien en 1893, además de postular el establecimiento de aquellos depósitos, no dudaba en aconsejar la creación de una aduana marroquí dentro de las propias ciudades argelinas de la frontera, como en Melilla, pues para el Majzen "con tal de que continúe ingresando los derechos de aduana (en principio un $10 \%$ ad valorem) que toda mercancía que entre en sus estados debe pagar a los amines, poco le importa que los perciba en Uxda o en Melilla. En rigor, para facilitar esta operación, se le autorizaría a percibir en Marnia — ciudad argelina- (los derechos) tal como los españoles lo toleran por Melilla" (15).

El problema para el rival comercio argelino no era sólo de derechos del tráfico comercial franceses o marroquíes, sino también de costes de transporte, por lo que, en cualquier caso, de no variar estos siempre salían más favorecidas las mercancías entradas por la ciudad española.

Repatriadas las tropas llegadas a Melilla durante el aparatoso conflicto de Sidi Guariach en la primavera de 1894, el comercio volvió por sus cauces anteriores pero ahora con mayor volumen, una vez finalizado el estado de alarma entre las tribus cercanas a la ciudad. estado que había paralizado todo el movimiento comercial. "Como estos obstáculos han tenido en Melilla el carácter de permanentes, claro es que sin ellos las transacciones mercantiles habrían sido mucho mayores..." (16). Las expectativas eran optimistas y quienes no estaban obsesionados por otros aspectos más llamativos de la ciudad así lo veían. Como José Boada y Romeu, periodista presente en la plaza durante el conflicto. "(Melilla)... ciudad que tomará mucho incremento si el comercio logra desarrollarse en la proporción que hay derecho a esperar de la excelente situación que ocupa" (17). El buen hacer, la buena mano, tan rara en Melilla con otros gobernadores, del nuevo comandante general don Rafael Cerero "normalizó la situación creada por la campaña, suavizó las relaciones con los fronterizos y expulsó a gran parte de la gente malcante que había acudido durante los sucesos" (18). La labor fue continuada con el mismo buen talante por su sucesor el general Alcántara.

Ya en estos años el volumen del comercio alcanzaba la cifra optimista de los cinco millones de pesetas de ventas a Marruecos, y 360.000 la de las compras, cifras que ni los más benevolentes de los candorosos participantes en el Mitin del teatro de La Alhambra hubiesen podido imaginar 
diez años antes, cuando abogaban por un incremento de las relaciones hispanomarroquíes basado, sobre todo, en el comercio bilateral. Claro que lo que Coello, Azcárate, Saavedra, Carvajal y Costa pretendían era más que nada el incremento de la penetración comercial española y de las casas comerciales peninsulares. Pero, en este aspecto, se hubiesen sentido enormemente frustrados, pues los productos procedentes de la península apenas contaban en el global de las transacciones, por tres razones fundamentales:

a) El comercio de Melilla estaba casi en su totalidad en manos de casas comerciales hebreas, la mayoría de cuyos miembros ni siquiera tenían la ciudadanía española. Es lamentación continua de particulares y entidades de todo tipo durante el siglo XIX y principios del XX. Así, la Comisión de Estado Mayor encargada de hacer una "Memoria descriptiva de Melilla" y su campo por orden del General Martínez Campos, General en Jefe de las tropas estacionadas en Melilla durante la corta guerra de Margallo, afirma en la misma: "Melilla es un puerto franco; su comercio, casi exclusivamente, se encuentra en manos de hebreos, que obtienen por este medio pingües ganancias con los productos que venden, procedentes casi todos de Francia y Gibraltar". (19) Confirma el marino don Pedro Guarro el monopolio comercial a los hebreos, pero se opone a lo que entonces solicitaban algunos al Gobierno: su expulsión de Melilla. El señor Guarro, bien al contrario, estima que la forma de negociar de la minoritaria pero activa colonia hebrea debía más bien constituir un ejemplo para todos, pues "en la mayoría de los casos empiezan con una simple mesa o como mucho una pobre barraca y en pocos años se convierten en empresas con fuerte capital. Los españoles no servimos para el negocio y nos quedamos atrás" (20).

b) Los productos españoles no podían competir con los extranjeros, sobre todo franceses e ingleses, de precio muy inferior y adaptados, en su mayoría, al gusto de los cabileños. Las casas comerciales españolas miraban con distancia al prometedor mercado magrebí, y mientras agentes comerciales franceses, ingleses e incluso alemanes se acercaban por Melilla para estudiar el mercado, la presencia de agentes españoles era prácticamente nula.

c) Las comunicaciones con la península eran escasas e inestables. Sin embargo, Francia e Inglaterra mantenían líneas de vapores fijas procedentes de Argelia y Gibraltar con escala en Melilla y otros puertos y orientación predominantemente comercial, siendo los fletes considerablemente más bajos que los establecidos por los vapores-correos españoles. 
Aun estas condiciones no puede negarse que el comercio espanol creció bastante desde 1893 , siendo como había sido casi nulo en épocas anteriores.

Por eso la "Revista de Geografía Comercial", en su número del tercer trimestre de 1895, daba para Melilla, en las cifras correspondientes al comercio exterior de España, las siguientes:

Exportación por Melilla, 2.109.769 pesetas

Importación por Melilla, 423.681 pesetas

Cifras quizá demasiado elevadas a nuestro parecer y que no reflejan con exactitud el comercio hispanomarroquí pues en su mayor parte pertenecen a productos de consumo interno en la ciudad y a objetos y mobiliario destinados al uso de la población melillense.

De forma muy genérica, y con gran variabilidad según los años, puede decirse que el comercio por Melilla era en un $40 \%$ procedente de Francia, un 35\% de Inglaterra, un 15\% español y el resto de otros países incluido Marruecos.

Este panorama apenas esbozado. se mantuvo en las líneas anteriores sin grandes variaciones hasta finales del siglo.

Parece obvio decir que la prosperidad económica del pequeño 108 territorio indujo un aumento correlativo de población llegada al aviso en las poblaciones del sur español de las nuevas condiciones socioeconómicas en la zona, aun cuando los inconvenientes que apuntábamos al comienzo de este trabajo no habían variado sustancialmente, y sólo la seguridad personal de los habitantes podía considerarse como distinta a la habitual en épocas anteriores. Punto nada irrelevante desde el punto de vista de la psicología del aspirante a la inmigración.

Por supuesto, no sólo el auge comercial fue causa del incremento de población. Otras causas no desdeñables acompañaron al tráfico mercantil. Por ejemplo, el aumento de la guarnición, que de los 1.560 hombres que había antes de la campaña de 1893 (21) pasó a los 2.446 hombres de dotación permanente en julio de 1894 (22). y unos 3.500 un mes más tarde al crearse un nuevo regimiento de Infantería para Melilla (23). En realidad, aun cuando esto es muy difícil de demostrar, es posible que el incremento de la guarnición tuviera mayor influencia a la hora de atraer nueva población a Melilla, pero no puede ignorarse que el mayor tráfago del comercio trajo consigo un incremento de la recaudación por arbitrios 
municipales y, por consiguiente, la realización de nuevas obras de infraestructura urbana que empleaban mano de obra de nuevo asiento en cantidad difícil de estimar.

Al mismo tiempo, la construcción de nuevos barrios - Carmen, Polígono, pabellones- en los que alojar la creciente población, dio trabajo a numerosos jornaleros, clase social la más numerosa y móvil de la ciudad empleada en los más diversos y aun dispares trabajos según la trayectoria vital de la incipiente ciudad.

\section{EL CAMBIO DE SIGLO. COMIGNZAN LAS DIFICULTADES}

A medida que Francia iba tomando confianza en su extensa "zona de influencia" veía con mayor claridad el peligro que contra sus intereses suponía la prosperidad comercial de Melilla; con tanta mayor razón cuanto que desde siempre los franceses consideraban todo el territorio marroquí hasta el Muluya como territorio argelino, siendo el Muluya, según ellos, su frontera natural (24).

Las pequeñas medidas adoptadas para contrarrestar la pujanza melillense no habían dado el resultado apetecido.

A finales del XIX Melilla acaparaba todo el comercio desde el Tafilalt, a través del largo y ancho valle del Muluya y su cuenca hidrográfica, del Garet y de la mayor parte del Rif, según Dechaud (25). La misma Uxda, ciudad comercial rayana con la frontera argelomarroquí, recibía la mayor parte de sus productos desde Melilla. Los productos franceses estaban gravados por derechos de aduana excesivos, hasta tal punto que las cabilas cercanas a Argelia preferían dirigirse al mercado melillense pese a los gastos que ocasionaban los largos viajes, incluidos los "zettat" obligados a pagar como peaje a algunas de las cabilas por cuyo territorio transitaban. A Uxda llegaban las caravanas procedentes del Figuig por lo que puede decirse que los productos de importación de Melilla llegaban hasta tan lejano punto de los confines argelomarroquíes. Los productos, en general, eran un 20\% más baratos comprados en Melilla que en el mercado argelino (26).

En 1893 hubo un intento de convertir la ciudad argelina de Marnia en una nueva Melilla sin que se llegara a adoptar medida alguna, medida que sin duda hubiese supuesto un duro golpe para el comercio de esta ciudad.

Un decreto francés de diciembre de 1896 permitía una cierta franquicia para mercancías en tránsito hacia Marruecos y los oasis saharia- 
nos, sobre todo para los azúcares, cafés, tés y alcoholes para perfumería y farmacia, siempre que fueran a ciertos puertos argelinos. La disposición no dio el resultado apetecido, debido a que los gastos de transporte seguían siendo muy elevados hasta el punto de que aún en franquicia el coste total del producto era muy superior al mismo traído desde Melilla.

En 1899 las Cámaras de Comercio de Argel y Orán dieron la voz de alarma, viendo el crecimiento inquietante del comercio melillense. Desde varios años antes aparecían por la vieja ciudad española exploradores franceses, algunos comisionados por el Residente General en Argelia, para observar detenidamente el movimiento generado por las nuevas circunstancias dadas en la zona tras cuatro siglos de inmovilismo y apatía. Duveyrier, Moulieras, Segonzac, René-Leclerc y otros tienen ocasión de comprobar "in situ" que Melilla ya no es la fortaleza olvidada, el presidio inútil que siempre creyeron que fue. Pese al evidente desprecio que hacia Melilla y España se observa en las notas dejadas por los ilustres viajeros (27), no cabe duda de que sus informes en Argelia dejaron huella, y prueba de ellos es la Memoria que las citadas Cámaras de comercio argelinas dirigieron al Gobernador del territorio impulsándole a contrarrestar la supremacía comercial de Melilla en el nordeste marroquí. La reacción no se hizo esperar, y en 1901 las Cámaras francesas aprobaban la creación de los llamados "depósitos francos" de Marnia y Beni Unif, primer paso hacia un desplazamiento del comercio en favor de los intereses franceses. Las mercancías entradas por Orán y Nemours con destino a Uxda (por Marnia) y Figuig (por Beni Unif), quedaban libres de todo derecho, pagando sólo almacenaje y escolta (28). De momento la amenaza francesa fue ignorada por las autoridades españolas, debiéndose reconocer que la única actuación posible de forma inmediata hubiese sido el reducir o eliminar los derechos de arbitrios percibidos por la Junta municipal por aquellas mercancías entradas en Melilla en tránsito hacia Marruecos.

Efectivamente, las tribus del Angad, las de Dahra y el Figuig cambiaron su destino pasando a comprar en los nuevos depósitos francos de la frontera. Este sistema, que pretendía mejorar la anterior situación para el territorio argelino, ocasionó un nuevo e inesperado problema. La extensa frontera argelomarroquí, y sobre todo el amplio espacio abierto a los confines del sur permitían que las mercancías vendidas en franquicia a Marruecos volviesen a Argelia en forma de contrabando, dados los precios sustancialmente 
más bajos de aquellas, lo que trajo consigo por una parte una disminución de los ingresos por aduanas y por otra una baja importante de las ventas de los productos no acogidos a la franquicia de los "depósitos francos" (29).

Quedaban, sin embargo, fieles al mercado de la plaza española todas las tribus marroquíes situadas sobre el eje del Muluya, tribus para quienes la distancia a la frontera de Argelia no compensaba los gastos del viaje. Debdú se convierte en cabecera del tráfico gracias a la numerosa y activa población hebrea. Algo había cambiado desde que el intrépido Foucauld pasara por la pequeña población; entonces el principal comercio de Debdú era con Argelia (30).

$Y$ es en este momento precisamente en que el mercado de Melilla va perdiendo bazas ante la jugada de Argelia cuando sobrevienen las revueltas impulsadas por el Roghi Bu Hamara contra Muley Abdel Aziz, revueltas que se suceden sobre parte del hinterland comercial de la plaza.

Pero así como los franceses se frotaban las manos satisfechos ante esta nueva y propicia situación, si en realidad y tal como siempre se sospechó no fue creada por ellos, que les permitía pescar en río revuelto cuando ya apenas disimulaban sus miras puestas como mínimo en el desplazamiento de sus fronteras hasta la orilla derecha del Muluya; así como para los franceses, insistimos, era una ocasión favorable para encontrar cualquier pretexto que les permitiera intervenir en defensa de sus intereses, los gobiernos españoles dejaban pasar el tiempo sin tomar iniciativa alguna dirigida a que los derechos adquiridos por Melilla fueran respetados, apoyándose en el deteriorado "statu quo". Las caravanas procedentes de la zona interior comienzan a sufrir las consecuencias de un territorio convulso, sin autoridad definida, sometidas al capricho de las cabilas de paso, en las que debían sufrir "impuestos" de zettat muy elevados en el mejor de los casos, si no robos y violencias personales que hacían cada vez más peligrosa la aventura comercial.

FRANCLA Y EBPAÑA. DO8 FORMA8 MUY DISTINTAS DE BNTBNDER RL "PROBLEMA DE MARAUECO8"

El problema de Marruecos, una frase suficientemente ambigua como para disfrazar lo que en realidad era un propósito de intervención en el país vecino, por parte de al menos cuatro países europeos: Francia, Inglaterra, España y Alcmania. 
La intención no era nueva ni mucho menos. Podemos remontarnos en el tiempo hasta finales del siglo XVIII, y como ejemplo más palpable el propósito de Godoy de invadir Marruecos aprovechándose de los buenos oficios en el país magrebí de Ali Bey el Abbasi.

Pero a principios del XX todas las apariencias de respeto hacia un país independiente representado en la persona del Sultán habían desaparecido. Francia no ocultaba su intención de invadir Marruecos y para ello lo único que necesitaba era un pretexto, una justificación para acabar con el controvertido "statu quo" que cada día se convertía más y más en una ficción.

Desde la Conferencia de Berlín, en la que la palabra "protectorado" se utilizó demasiado y en la que el artículo 35 hacía mención a una "autoridad suficiente para hacer respetar los derechos adquiridos y la libertad de comercio y tránsito", estaba claro que los últimos territorios africanos aún sin ocupar terminarían por entrar en el juego de las apetencias de los países colonialistas, y en el caso de Marruecos parecía evidente que si la "autoridad suficiente" no era la que podía imponer el Sultán, sería alguna otra nación quien la impusiera más tarde o más temprano.

El intento de acucrdo entre España y Francia de 1902, el convenio de 1904 entre Francia e Inglaterra, y el posterior del mismo año entre la primera y España, eran pasos que iban en el mismo sentido. El "tangerazo" de 1905 y la Conferencia de Algeciras del siguiente año solamente quedaron como maniobras dilatorias que no iban a impedir la voluntad, sobre todo de Francia, de intervenir directamente en los destinos del país magrebí.

El primer paso ya estaba dado por los franceses al nombrar Alto comisario de la frontera argelomarroquí al general Lyautey, comandante general de la División de Orán, "valiente militar, economista y político distinguido", según Delbrel en frase sugerente, quien con su concepción del programa de intervención mixto político-comercial-militar, comenzó a poner los jalones previos a los avances de Francia hacia el territorio marroquí de la derecha del Muluya. Antes de la Conferencia de Algeciras (1906) ya Francia había colocado una sólida cabeza de puente hacia el territorio vecino, a la espera de la ocasión y el pretexto necesario.

En el ínterin se potenciaban los zoco francos estableciendo sólidas relaciones con las tribus limítrofes a base de "lefuf" (31) acordados con los jefes principales, no dudando en emplear a sus oficiales como agentes comerciales en lo que se llamó sistema "mixto-militar", por el que se 
empleaba la fuerza estrictamente necesaria, pero acompañada inmediatamente de una intensa acción comercial con el fin de establecer fuertes vínculos entre Francia y las tribus.

Partiendo de los confines argelomarroquíes, mal definidos desde la batalla de Isly en 1844, Francia fue avanzando a pasos cortos pero seguros. En junio de 1904 es ocupada la alcazaba de Ain Beni Mathar en territorio marroquí, creando el zoco de Berguent, gracias a la buena labor de los "Bureaux Arabes", mercado que desde 1906 se habría de convertir en uno de los centros comerciales más importantes del este marroquí. Con la ocupación de Uxda el 29 de marzo de 1907 bajo un ridículo pretexto, se confirma la voluntad de Francia de no ceder en sus pretensiones, una vez que la Conferencia de Algeciras dejó la cuestión tan ambigua que podía entenderse como se quisiera.

¿Qué hacía España mientras tanto? Prácticamente nada, dejar pasar el tiempo a la espera de que las cuestiones se resolvieran solas, política por cierto seguida en líneas generales hasta 1925 con las secuelas que todos conocemos.

$Y$ no por falta de advertencias. Se pueden encontrar todas las que se quieran desde 1860 a 1909. Cándido Lobera señalaba en 1901, cuando se veían ya nítidas las maquinaciones francesas: "Las aspiraciones de Francia deben preocuparnos más que las de cualquier otra nación" (32). Por supuesto que la voz de don Cándido no llegaba entonces hasta Madrid, como llegaría unos años más tarde a través de su diario El Telegrama del Rif, pero ya cuando los acontecimientos venían precipitados. Lobera comprobaba desde Melilla que la labor francesa iba en contra de los intereses de la ciudad española, precisamente en un momento en que "la actividad del comercio en grande escala con las cabilas, el aumento de relaciones comerciales es indispensable si queremos no dar pretexto ni base para que se nos elimine de la cuestión marroquí" (33). Cuando ya Marte y Mercurio se aprestaban a ir en amistosa compañía, puesto que "no basta la espada para engrandecer real y positivamente las naciones... y que el desarrollo comercial y el de colonización son los verdaderos derroteros de engrandecimiento que deben seguir los pueblos que aspiran a ser algo" (34).

En aquel instante las transacciones comerciales Melilla-Marruecos alcanzaban los 8.700 .000 pesetas, una cifra muy notable si la compara- 
mos con los 9.300.000 peselas que alcanzaba el comercio total de España con Marruecos en la misma fecha.

En esta misma cifra de intercambios comerciales entre Marruecos y Argelia venía a ser de unos 17.000 .000 de francos; pero en su mayor parte correspondía a exportaciones marroquíes hacia la colonia francesa. Conservaba Melilla la primacía en el comercio de importación gracias a su privilegiada situación que no a las buenas artes de nuestras autoridades (35).

En la sesión del Senado correspondiente al 17 de febrero de 1902. el que fuera promotor de los inoperantes Centros Comerciales Hispanomarroquíes señor Labra, interpelaba al duque de Almodóvar sobre el peligro argelino, contestando éste que "era preciso, en efecto, poner a MeliIla en condiciones de luchar contra esta nueva concurrencia" (36). No era tan nueva, pero, ¿fue por esto por lo que se declaró de interés general el puerto de Melilla? Probablemente. Pero a estas alturas yo no era suficiente: lo necesario era, por una parte no perder los mercados ganados por Melilla en el último tercio del anterior siglo, y por otra incrementar el comercio hispanomarroquí, cuya pobre presencia se estimaba en una escaso 8\%, muy lejos de Francia e Inglaterra.

Ambos objetivos tenían mala solución. pues para alcanzar el segundo hubiese sido preciso cambiar la mentalidad del industrial y del comerciante español, y para el primero actuar en la misma dirección que Francia, utilizando sus mismas fórmulas, cosa que estaba muy lejos de los propósitos de los gobiernos españoles, todavía a vueltas con la política del "statu quo" en un momento en que ya casi nadie creía en ella. En realidad era una forma cómoda de no crearse complicaciones, aunque las complicaciones más tarde o más temprano habrian de surgir, y cuando surgieron ya era demasiado tarde. Las advertencias no fueron escuchadas. Ante la agresividad comercial de Francia "en breve Melilla será la esclava manumitida". decía Antonio Ramos (37).

\section{EL ROGHI BU HAMARA}

siglo $X X$.

Esta es, en síntesis, la situación de Melilla en los comienzos del

Coincidiendo con el cambio de signo de la expansión comercial de la ciudad, se desarrollan en el territorio marroquí que podemos llamar 
de influencia, los hechos ya mencionados cuando se hizo alusión a Roghi Bu Hamara y que habrían de influir decisivamente en el rumbo de aquella.

Desde 1903 comienzan a sucederse en la zona de Taza varios incidentes entre el llamado Pretendiente, aventurero que se hace pasar por el príncipe Mohammed, y el sultán Abdelaziz, este último no bien visto por buena parte de sus súbditos debido a sus veleidades proeuropeas. Aprovechándose de este talante malhumorado del pueblo marroquí, el Roghi quiso atraer a su causa a las tribus cercanas a Taza, ya en abierta oposición al Sultán. La respuesta de éste mandando tropas que se opusieran a los manejos de Bu Hamara inició una serie de disturbios entre las cabilas del noroeste magrebí que alteró por completo la frágil tranquilidad del territorio. En estas circunstancias de "anarquía" era lógico que sufrieran en primer lugar las operaciones de comercio, dada la inseguridad de los caminos, que no aconsejaba el paso de caravanas, fácilmente acechadas por las temibles cabilas nómadas, siendo asaltadas y despojadas en numerosas ocasiones.

Los primeros años, sin embargo, no fueron especialmente onerosos para Melilla, pese a que la intranquilidad se notó igualmente en las cabilas cercanas a la ciudad. Teniendo en cuenta los manejos de Francia sobre su frontera argelina, las cifras de comercio entre 1901 y 1904 reflejan un tono sostenido, aunque lejos posiblemente de las esperadas por la progresión observada en los últimos años.

Gabriel de Morales nos da las siguientes cifras que, como todas, creemos hay que tomar con prevención y fundada sospecha:

$\begin{array}{lcc}\text { Año } & \text { Importación } & \text { Exportación (en pesetas) } \\ 1901 & 7.879 .599 & 816.646 \\ 1902 & 8.219 .832(38) & 1.191 .943 \\ 1903 & 10.190 .553 & 1.109 .909 \\ 1904 & 8.515 .029 & 1.287 .242\end{array}$

La población de la ciudad se mantiene, incluida una guarnición de unos 3.500 soldados, sobre los 9.000 habitantes durante todo el periodo.

Las cifras anteriormente expuestas parecen dar a entender que la creación de los mencionados "zocos francos" en las fronteras argelinas no afectó al comercio de la ciudad. Sí le afectó, pero sobre todo en el sentido de cortar un mercado en franca expansión que hubiese hecho crecer con 
mucha mayor rapidez población y ciudad. Parte de la posible pérdida de aquel mercado fue compensado con el incremento de las relaciones con las cabilas cercanas y del interior del Rif.

En 1904 se dan dos hechos que aparentemente suponen dos pasos más en la dirección que parece intuirse desde tiempo antes: la intervención de España en los destinos marroquies. Más aparente que real hasta 1909. Por una parte se firma con Francia el Tratado de aquel año, en el que se confiere a España de forma ya inequívoca la facultad de intervenir en la parte norte de Marruecos, reservándose Francia la parte del león. es decir, la única que merecía la pena desde un punto de vista colonialista: pero, sobre todo, la facultad de dominar la cuenca del Muluya y el camino de Taza, cortando de raíz las viejas aspiraciones de algunos de nuestros intervencionistas destacados que abogaban porque nuestro país tomara toda la zona norte incluidas Taza y Fez.

En ese mismo año asienta sus reales en Zeluán el Roghi. La presencia del pintoresco personaje habría de transformar, sin quererlo él mismo, los destinos de Melilla; cambiando en cierto modo los de España como lógica consecuencia.

En octubre de 1905 ya había concedido a una compañía francesa los terrenos que necesitaba para fundar una factoría comercial en la llamada Restinga. La alarma cundió en Melilla, puesto que se trataba de una clara ingerencia francesa en territorio asignado a España por el tratado recientemente firmado con Francia.

Morales afirma que si la factoría hubiese tenido éxito la ruina de la ciudad era inevitable, "y una prueba más de la buena fe con que los franceses guardaban los tratados recientemente concluidos" (39).

Desde el primer momento y ante la presión del comercio local, las autoridades de la ciudad, representados en la persona del general Marina, llegado poco tiempo antes, hicieron lo posible por acabar con tan peligrosa situación, que de alguna manera pretendía reproducir a las puertas de Melilla lo que Francia experimentaba en su zona de influencia. Afortunadamente la factoría fue desalojada en el mes de marzo siguiente, desapareciendo el peligro, sí, pero quedando el resquemor de lo que podría pasar si España descuidaba sus intereses en la zona.

Desde aquel momento el Roghi continuó con una política de apaciguamiento con España, beneficiosa para Melilla que reanudó el tráfico 
con las cabilas bajo el manto tutelar del Pretendiente. L $\dot{\circ}$ os franceses observaban preocupados que los manejos de Delbrel laborando por su causa nacional no habían dado el resultado previsto. Aunque muchos pesimistas de la época insistían en que la estancia del Roghi en las cercanías de Melilla perturbó el normal desarrollo de la ciudad, y así lo afirman autores posteriores como Arques y Maldonado (40), Melilla relanzó las transacciones hasta el punto de que en Argelia llegó a temerse que la ciudad española volviera a tomar la primacía del comercio con las cabilas cercanas a Uxda (41). Además, en Melilla se asentaban casas comerciales argelinas para traficar a través de la ciudad fronteriza marroquí.

\section{EL HJEMPLO FRATTCBS}

Francia entendió las conclusiones del Acta de Algeciras (1906) como una victoria diplomática suya, y un aval — patente de corso, diríamos mejor- para su intervención, ya no disimulada, en los destinos del país vecino africano. Era evidente que solamente esperaba la ocasión propicia para poner en marcha el dispositivo que le llevara en dirección a Fez por el rápido camino de Tazza. Ocasiones no habían de faltar en una frontera tan extensa como la común entre ambos países. La prensa procolonista francesa no dejaba de advertir con machaconería sobre la "anarquía reinante en la frontera argelina”, una ficción para dar a conocer lo que siempre había sido así; no era nada nuevo. Lo que era reciente era la voluntad de Francia para terminar de una vez con el "statu quo" moribundo si no muerto ya desde Algeciras.

"Francia comprendió entonces, a sus expensas, que no era posible hacer nada con el Mjzen y que por consiguiente, debía basar su política sobre una inteligencia con las tribus" (42). Desde ese momento las Oficinas de Asuntos Indígenas toman la iniciativa pasando a desarrollar una hábil política mixta de intervención militar e inteligencia comercial con las cabilas con resultados mejor que buenos. Primero serían acuerdos con los nómadas de Mehaia y Beni Guild del Dahra marroquí; más tarde vendría la ocupación de la alcazaba de Ain Beni Mathar (junio de 1904), creando el mercado de Berguent con negativas consecuencias para Melilla desde 1906, y si no hubiese sido por la resistencia del viejo Bu Amama el camino hacia el interior del país hubiese sido más rápido. Hubieron de esperar al incidente de Marraquech para tener un pretexto sólido — para 
ellos- que les sirviera para ocupar Uxda el 29 de marzo de 1907. Con ello "no solamente consolidaba su inteligencia comercial y política con las tribus del Este marroquí, sino que también suscitaba, por no afirmarlo rotundamente, los disturbios de Beni Snassen, a fin de provocar un nuevo acto de presión sobre el Majzen, ocupando toda la zona Este marroquí comprendida entre el Kiss y el Muluya, de una parte; el Mediterráneo y la llanura de Angad, de otra" (43). "Después, —sigue Delbrel- Francia, ocultando esta política de bajo cuerda e inteligencia con las tribus, lanzará a los cuatro vientos: Nosotros no hacemos ocupaciones militares: nos limitamos a restablecer el orden en la zona marroquí que confina con nuestro territorio...".

Nótese que Delbrel escribe los párrafos anteriores un mes y medio antes de que comiencen los sucesos de Melilla. Está haciendo historia de la intervención francesa.

La ocupación de Uxda restringió el mercado de Melilla en aquella ciudad, aunque no llegará a desviar hacia ella todo el tráfico de las tribus del norte que escapaban a la acción directa de Francia, pues aún Melilla era comparativamente más barata que Uxda. Una caja de 100 kilos de azúcar costaba en Melilla 50 francos y en Uxda 58 (44). Solamente la distancia, con los gastos de transporte y los zettat kalibeños, desalentaban a las tribus del sur marroquí, como ya dijimos, de acudir al mercado de Melilla; era más barato acercarse a los zocos francos franceses. (45)

"Más tarde la política francesa invocará el mismo pretexto y se servirá del mismo sistema para ocupar la región del Za y extender su dominio más allá del Muluya, para abrir todos esos territorios... a la actividad de sus comerciantes, a la asiduidad de sus colonos y a las investigaciones de sus agentes mineros". La claridad de Delbrel es meridiana. La advertencia a las autoridades españolas no deja lugar a dudas.

La ocupación de Si Mohammed u Berkan (actual Berkane), cercana al Muluya, fue un aviso más que suficiente, coincidiendo aquella además con la desaparición de los depósitos francos y los impuestos de almacenaje y escolta hasta la frontera argelina, con un significativo descenso de los precios. En el momento en que Delbrel escribía su interesante informe, Francia amenazaba ya con ocupar el Aiun de Sidi Melluk, a un tiro de Taurirt, lugar de paso de las caravanas que desde Debdú concurrían a Melilla. 


\section{LA AGTUACION BSPAÑOLA HASTA LA MaRCHA DEL ROGHI}

La relación de hechos sucintamente expuestos líneas arriba, en cuanto a la política seguida por Francia en su zona de influencia, no podía naturalmente pasar desapercibida para España, y sobre todo para las autoridades de Melilla y principales agentes de la ciudad, para quienes no era indiferente lo que pasaba al otro lado del Muluya.

En 1904, cuando el Roghi establece su "trono" de forma permanente en Zeluán, la situación de Melilla es la siguiente:

Tiene una población de unos 11.000 habitantes, incluida la guarnición de 3.500 soldados (10.000 habitantes, según El Telegrama del Rif, (46) la mayoría oriundos de Andalucía. La Junta de Arbitrios acaba de estrenar su nuevo régimen cívicomilitar, y maneja un presupuesto de 540.747 pesetas, de los que su mayor parte son generados por los arbitrios sobre la importación de tejidos y azúcar y la exportación de huevos.

La principal actividad es el comercio, habiendo 191 casas extranjeras y 60 españolas, las primeras dedicadas principalmente al comercio con las cabilas y las segundas al mercado interior. De las 191 casas extranjeras 20 son casas hebreas importantes, destacando la familia Salama, David Melul y David Charvit, este último disfrutando del monopolio del comercio con el Roghi. Los hebreos, pues, acaparan casi todo el comercio, incluso el interno (47).

La actividad más rentable, sin embargo, no es el tráfico comercial sino la derivada de la propiedad inmobiliaria, también con preponderancia hebrea y basada en la carencia crónica de viviendas, con rendimientos que sobrepasan el $20 \%$ cuando lo normal en la península era el $4 \%$ (48). Se ha iniciado un tímido intento de colonización de los terrenos del campo exterior de Melilla que no alcanza para el autoabastecimiento de la plaza.

En enero de 1904, en su visita a Melilla, el exministro Villanueva promete la construcción del puerto; en mayo, el rey Alfonso XIII coloca la primera piedra.

La principal actividad portuaria es la derivada de la escala de vapores pertenecientes a las líneas comerciales francesas e inglesas, dato revelador.

Los gobiernos, siguiendo la tradición, apenas si hacen algo para promover los intereses de España en la zona. Las entidades particulares interesadas en el problema se pierden en palabrería inútil sin que se 
adelante cosa alguna. Los Centros Comerciales Hispanomarroquíes, que parecía iban a hacer una ingente labor, fundan una sección en Melilla que no lleva a ninguna parte muriendo por sí misma al poco tiempo. Todo son sabios consejos pero apenas si hay hechos prácticos.

En 1905 el general Segura, Gobernador de la plaza, comisiona al entonces capitán Lobera para que se desplace a Argelia y estudie sobre el terreno el funcionamiento de las eficaces Oficinas de Asuntos Arabes. Lobera no duda en aconsejar su fundación en las plazas africanas de España. "Muchos moros y hebreos hoy establecidos en Melilla procedentes de Argelia, donde tuvieron ocasión de tocar prácticamente las ventajas de las Oficinas árabes, dicen que en muchas ocasiones facilitaron sus negocios y convienen en los indiscutibles beneficios que a todos reportaría su creación" (49). El asunto queda congelado para mejor ocasión a la espera del "placet" del gobierno.

Decía Agustín Bernard (50) que la llegada del General Marina en noviembre de 1905 abrió para Melilla y España un nuevo periodo de actividad que llegaría hasta la campaña de 1909.

Pero no es que la personalidad del conocido general fuera trasunto de la del general Lyautey, ni mucho menos. Era que en aquel momento las naciones europeas preparaban su equipaje para acudir al tablero marroquí con las mayores ventajas, y al popular general le tocó vivir la época en que inevitablemente el nombre de Melilla tendría que aparecer si se llevaban a cabo las "buenas" intenciones que los gobiernos espanoles ponían de manifiesto de palabra ya que no de obra.

En la sesión de Cortes del 12 de diciembre de 1906, para debatir la aprobación del Acta de Algeciras, el Ministro de Fomento señor González Besada aseguraba que "el actual Gobierno, como los anteriores, como por los sucesores, (va) a la penetración comercial en Africa" (51). En esta política había que contar con las posesiones españolas del norte africano, y sobre todo con Melilla, magníficamente situada de cara a la penetración, fuera militar, o comercial o mixta (52).

También el señor González Besada se refería al peligro francés: "¿Cuál es el objeto de la ocupación de Uxda? Pues es bien claro". Estaba claro que las miras de Francia apuntaban a la estratégica ciudad de Taza como punto intermedio hacia Fez. Pero al mismo tiempo el senador Díaz Moreu se hacía y se contestaba la siguiente pregunta: : ¿Para qué hacemos nosotros el puerto de Melilla?... lo hacemos para llegar en las mismas con- 
diciones hasta Fez...; si por la construcción de estos puertos se deduce que se aspira a la penetración y que eso significa el problema de Marruecos, si se considera por el gobierno como un problema económico...".

Un problema económico había y para ello se hacía el puerto de Melilla, y el de Chafarinas... "para el comercio con el Muluya", como también afirmaba González Besada. Cinco millones de pesetas importaban ambos puertos, "cantidad completamente tirada al mar si no traen como consecuencia inmediata procurar los medios necesarios para que acuda a esos puertos el comercio de Marruecos" (53).

Obsérvese que ya se habla oficialmente de penetración en Marruecos y que las motivaciones esenciales tienen un evidente sustrato económico-comercial. En eso hemos de dar la razón a quienes hoy día insisten en Marruecos sobre el mito del "colonialismo espiritual", muy escaso en el fondo en la mayor parte de los adalides de la intervención española en el Magreb pese a la retórica abundante en aquel sentido desde el mentado Mitin de 1884 (54).

Desde 1905 los intereses de España y Melilla han tomado un nuevo sesgo con la aparición de las compañías mineras. Para complicar más la situación serán dos compañías, una francesa y otra española, quienes se disputen el codiciado mineral. Más aún, han de ser los franceses quienes tomen la iniciativa en este asunto.

En octubre de 1905, Alexander Baylle, representante de intereses franceses en el río Kiss, donde monsieur Say pretendía aniquilar a Melilla con una factoría comercial, apareció por Melilla con el fin de visitar al Roghi en su mansión de Zeluán y tratar con él de asuntos mineros. Gabriel Delbrel hizo la presentación, con tan buena mano que Bu Hamara le concedió la explotación de las minas de Uixan no sin asegurarse un buen rendimiento en el negocio. Desafortunadamente para Baylle para ponerlo en marcha hacía falta abundante capital, por lo que tuvo que ir en su busca, hasta que por fin dio con el señor Massenet, ingeniero de minas en París, quien para asegurarse la bondad de la empresa visitaría al Roghi en Zeluán en abril de 1907. Habían perdido año y medio y ello les fue fatal, pues en ese lapso temporal ya se estaba formalizando. su rival, el Sindicato de Minas del Rif, directo antecedente de la CEMR, en la persona del señor Macpherson, también solícito visitante de Bu Hamara. ya veremos que esta rivalidad aportaría lo suyo a los acontecimientos de 1909. 
Pero mientras los intereses mineros al principio sólo eran un proyecto, los intereses comerciales eran una realidad. En 1907, año que puede considerarse como malo para las transacciones por el estado del campo exterior marroquí, se alcanzan los 12.500 .000 pesetas en el tráfico de mercancías (55), es decir 16.947.509 toneladas entradas a través del puerto en ciernes, muy lejos ya de aquellas 1.500 aforadas en 1875 (56). Y si las condiciones del territorio vecino hubiesen sido las deseadas, las posibilidades del comercio melillense hubiesen sido enormes. Hasta cuatro veces más, según Caballero Puga (57).

El asunto interesa a todos los avisados, no es una cuestión puramente local. Gonzalo de Reparaz advierte sobre la condición de Melilla y su particular situación como cabeza de toda comunicación con el interior. Apoya sin disimulos la intervención, que no es sólo económica —debe serlo-, intelectual y social —el barniz civilizador-, sino también armada. Pacífica, pero armada (?). "Un justo medio entre la conquista militar y la continuación del statu quo" (58). El ilustre africanista hace una seria advertencia afirmando que si Francia llega a construir el ferrocarril de Taza, "todo el comercio rifeño y yebala derivarán por el ferrocarril hacia el Kiss" (59).

En el interior de Melilla se entiende la situación en la línea marcada por el ejemplo francés.

"Melilla es la llave que abre la puerta de comunicación con el Rif. España ha seguido y sigue una política de atracción mal entendida, que los rifeños interpretan como signo de debilidad y por eso no logramos imponernos como se han impuesto otras naciones, como sucede con Francia en Argelia... Esta nación que tiene posesiones lindantes con las nuestras no ve, no puede ver con buenos ojos en sanos principios de egoísmo internacional el esplendor de Melilla que ha de restar influencia al Kiss y la Argelia, y de ahí sus conocidos trabajos cerca de la insurrección marroquí y de ahí tal vez, y de un modo embozado e indirecto su oposición para que el puerto de Melilla fuera construido y que acabaría por sentar la preponderancia comercial de España en estas regiones" (60).

Otra muestra: "Si no conociéramos las altas dotes de mando, la discreción y el patriotismo del ilustre general D. José Marina le excitaríamos para que tomara o favoreciera las iniciativas encaminadas al engrandecimiento y prosperidad de Melilla, le encareceríamos la necesidad de seguir una política de atracción con las cabilas fronterizas, de cultivar amistades y 
entrar en inteligencia con los jefes de las mismas, como lo hacen nuestros vecinos con las tribus del Sur oranés; pero todo esto y mucho más lo sabe perfectamente el gobernador militar de aquella plaza..." (61).

El caso no ofrecía duda: "Melilla debe ser de hecho y de derecho el centro comercial de aquella comarca ${ }^{n}(62)$. Régimen civil, ferrocarril a Fez (!), reducción de fletes, agentes comerciales, agencia del Banco de España, servicio de correos, cable telegráfico, política de tolerancia, mezquitas, hospitales y escuelas para indígenas, atracción del elemento hebreo. En fin, todo lo necesario para "convertir nuestras posesiones en verdaderos centros comerciales" (63).

Porque Melilla "no es sólo una plaza fuerte española; es un centro comercial admirablemente situado con relación a toda la región del Rif" (64).

Pero en 1907, como ya hemos apuntado más arriba, el campo rifeño no estaba tranquilo. Los avances franceses sobre el "belad" marroquí, las intrigas de las compañías mineras y, sobre todo, las luchas incesantes entre partidarios del Pretendiente y Muley Hafiz, y los de este con los de Abdelaziz, habían frustrado las expectativas que para un espectacular progreso de Melilla se habían fundado. La población sobrepasaba los 14.000 habitantes y se extendía por el llano donde poco antes sólo había juncos y palmitos.

En aquel momento el mercado de Berguent, aunque no tan feroz como se presumía, era un competidor peligroso para Melilla. "No debemos considerarlo enemigo pequeño", decía El Telegrama del Rif en agosto de 1907, "pues está llamado a ser el principal mercado de la frontera argelina por su envidiable situación, el día que la línea férrea de Orán-Bedeau se prolongue hasta Berguent..." (65).

Pero el mayor peligro, insistimos, era la situación del campo marroquí, en el que los intentos del Sultán para controlar las fuerzas en litigio habían sido vanos. "Los daños que la situación, envenenando y acentuando la anarquía habitual en el Rif, causaba a la plaza (de Melilla) eran evidentes. El comercio de Melilla celebró durante aquel tiempo varias reuniones para pedir auxilio y solución al Gobierno..." (66)

En mayo de 1907 llega la mehalla imperial a la Restinga. El campo cercano se revuelve, los conflictos arrecian y el comercio se paraliza. La mehalla no pacifica la zona, incapaz de soportar la presión rifeña, y en 
enero de 1908 tiene que acogerse a la benevolencia de nuestras autoridades que le dan asilo en la plaza.

Precisamente las autoridades creen que han aprendido la lección francesa. Hay que evitar que nuevos peligros acechen a Melilla. Y para ello es preciso ocupar puntos en el vecino país... para no permitir que los ocupe otro. El General Marina y el Gobierno dicen que dado que el Sultán no puede asegurar la tranquilidad del territorio, España, en cumplimiento de lo acordado en el Acta de Algeciras, deberá sustituir al incapaz poder majzeniano.

El motivo real era otro, como muy bien explica Lobera y confirma Ruiz Albéniz (67), pues la ocupación de la Restinga y Cabo de Agua no garantizaban paz alguna; lo que sí garantizaban era que no se estableciese en aquellos puntos una nueva factoría comercial con grave peligro de los intereses españoles en Melilla. Efectivamente, el 14 de febrero de 1908 se ocupa la Restinga, y el 12 de marzo siguiente Cabo de Agua, este último además excelente punto de partida para una eventual intervención en Marruecos a través del valle del Muluya, el llamado Bidasoa marroquí por Díaz Moreu, donde se encontrarían españoles y franceses en plano no muy largo. Con este experimento positivo se tomó nota para futuras ocasiones. Por ello decía el diputado radical, el africanista Julio Cervera: "cuando intervienen en esa política elementos militares se obtiene algo positivo". De muy distinta forma opinaría un año más tarde.

La ocupación de Restinga y Cabo de Agua soliviantó a las cabilas quienes pasaron factura de ello al año siguiente, pero afortunadamente en aquel momento ya tenía tomado el Roghi las riendas de la cuestión, garantizando por sus propios medios la paz entre las cabilas y haciendo lo posible para que, por fin, los intereses españoles puestos sobre el terreno gozaran de garantías y fueran bien acogidos, si no por gusto, al menos por la conveniencia material, y en último caso por la fuerza. Comienzan a penetrar en el Rif pies foráneos, situación original después de 400 años. Las compañías mineras encuentran todas las facilidades, a las que no son extrañas el dinero repartido con profusión, pero sobre todo el comercio toma unos vuelos insospechados gracias a la franquicia de paso que asegura la "pax roghiniana".

Las cifras son elocuentes. Al terminar el año 1908, el comercio importación-exportación llega a los 20.000 .000 de pesetas, cifra asombrosa para una ciudad de 16.000 habitantes (68). 
¿Cómo, se preguntará alguno, se explica que habiendo perdido Melilla gran parte de su zona comercial desde 1900, las cifras de comercio son tan elevadas ocho años más tarde? La Cámara de Comercio de Melilla lo explicaba en el III Congreso Africanista de diciembre de 1909. Porque "los moros, al igual que los demás pueblos, acrecientan sus necesidades por el trato con los europeos, y esto explica que las mismas cabilas consuman hoy mayores cantidades de artículos de todas clases que hace veinte años" (69). Además del poder adquisitivo mucho más elevado de que gozaban los numerosos rifeños que se desplazaban a Argelia en la época de la recolección, y que empleaban gran parte de sus recursos en la compra de productos del mercado melillense.

La situación era propicia para poner en práctica alguna de las buenas intenciones gubernamentales sobre la acción de España en el norte africano. Así, otro ministro de Fomento, el señor García Prieto, pretendía "crear centros de expansión comercial" y al mismo tiempo primar de alguna forma la exportación española hacia Marruecos. De aquellas buenas intenciones solamente quedarían un zoco que no llegó a ser, una enfermería indígena que apenas funcionó como tal y un silo para los cereales rifeños que no se llegó a estrenar hasta la campaña, cuando fue cedido a la Administración Militar.

Pero si no las iniciativas gubernamentales, los intereses de Melilla iban por el buen camino gracias a la labor protectora del Roghi, el falso Sultán que señoreaba la zona con la general satisfacción de entidades y particulares. Comisiones científicas diversas se atreven a penetrar en Marruecos circulando por los antes peligrosos caminos sin temor a sorpresas.

El comercio de Melilla entra en la zona sin esperar a que sean los propios cabileños quienes vayan a Melilla a demandar los productos que cada día les son más indispensables.

"Los moros se han hecho conservadores, pacifistas, amigos de la comodidad y entusiastas del progreso", decía con pésimo ojo clínico Antonio García Pérez en 1908, ... "y se hacen más españoles a medida que España es más africanista en su política externa" (70). "Cuán admirable es la política que se está incubando en Melilla por afortunada dirección", "Marruecos ser grande cuando tener corazón moro y cabeza cristiana", decía al inocente capitán un cabileño, y según el oficial "eran el sentir del pueblo indígena circundante a Melilla". Y todo ello "gracias a las minas, al 
comercio, al traslado del presidio, al cambio de política". (71) Las minas. "A su sombra comenzaban a crearse industrias en Melilla; a planearse negocios españoles", es decir, "vida para nuestra plaza y medio de hacer efectiva, sin que hable la pólvora, la penetración pacífica armada" (72).

\section{EI COMIENZO DEL FIN DE UNA F́POCA}

La política seguida por el Gobierno Maura de dejar abandonado al Roghi a su suerte para no alterar la ficción del poder de Muley Hafiz trajo como consecuencia el precipitado abandono del Pretendiente de su sede de la Alcazaba de Zeluán.

Las resultas de tal actitud no se hicieron esperar. Todo el artificio montado para el control de las cabilas se vino por tierra, y estas comenzaron a "estar en república", es decir a campar cada una por sus respetos, estableciendo las normas de cada jefecillo de cabila o aún de poblado quisiera imponer. Los trabajos en las minas y en los ferrocarriles se detuvieron y el comercio de la ciudad cayó bajo mínimos.

Bu Hamara abandonó Zeluán el 4 de diciembre de 1908.

Diez días más tarde escribía el General Marina al Ministro de

Estado, señor Allendesalazar, advirtiéndole de que las cabilas no podían garantizar la seguridad exterior, proponiendo que los trabajos mineros continuaran suspendidos, a la espera de la llegada de tropas majzenianas (!). El Gobernador de Melilla reconocía que no había autoridad en el campo con quien tratar por no tener las cabilas siquiera determinadas sus propias autoridades. En una palabra: Melilla volvía a quedar sitiada como en los viejos tiempos (73).

Ya el día 18, en carta a Maura, Marina insiste en las dificultades para llegar a un acuerdo con las cabilas, y "si el Sultán no lo remedia en un plazo perentorio, lo que España ejecute tendrá que ser empleando la fuerza, y para eso será preciso aumentar los medios militares con que cuenta Melilla..." (74).

En carta de contestación a la anterior, de fecha 23 del mismo mes, Maura dice: "Y como la inseguridad en el campo moro es asfixiadora de la civil y comercial y de la expansión política de Melilla, tenemos el más vivo interés en conseguir que cese cuanto antes la paralización que la anarquía kalibeña nos causa" (75). Siempre con gran precaución puesto que Francia, Inglaterra y Alemania nos observan. "Por grande que sea nuestra 
repugnancia a emprender avances apoyados en nuestras propias armas, sigue Maura, ...todos los intereses españoles en el futuro sobre la margen izquierda del Muluya nos impondrán imperativamente el empleo de los medios indispensables para salvar el prestigio de España a todo trance". Ahora bien, la abstención que de momento se impone "podría verse contrariada por agresiones que no nos fuera licito dejar impunes" (76).

En los párrafos anteriores, extractados de una documentación más extensa que abunda sobre lo mismo, se adivina con claridad lo que ha de ser una fatalidad anunciada.

Mientras tanto en Melilla se observa el proceso con enorme preocupación. La Cámara de Comercio alerta sobre las graves consecuencias que la situación imperante va a traer para la ciudad.

El 8 de enero de 1909, el diario local, en un dramático editorial bajo el título "El mercado de Melilla está enfermo", dice: hacerse crónica.

Sí, está enfermo, con dolencia amenazadora de

... Se resiente de la falta de demanda; los compradores no acuden a la plaza como antes acudían y este alejamiento se debe sin duda a la inseguridad de los caminos que hacen aventurada la salida de las caravanas que en tiempos no lejanos venian a Melilla.

La situación del campo produce aguda crisis al comercio de Melilla".

Es necesario... poner remedio a los males de Melilla.

Cuantos en esta plaza vivimos, sabemos perfectamente a qué atenernos, tenemos visión clara y exacta del asunto. Lo que hace falta es que al otro lado del estrecho, en Madrid, se opine como aquí se opina (77). La alusión al empleo de la fuerza es palpable.

EI Gobierno estaba bien informado de lo que ocurría, porque el General Marina se cuidaba muy bien de ello: "El Gobierno estaba advertido, y el único elemento de juicio que tenía para formar concepto de lo que pasaba en Melilla eran los informes que yo le daba", decía el General a los miembros de la Comisión de Responsabilidades en 1923 (78). Los informes 
del general, y, añadimos nosotros, la habitual lectura de El Telegrama del Rif, tal como reconocieron algunos primates en las sesiones del Congreso de mayo de 1909.

La ciudad de Melilla se ahogaba por momentos. Al no importarse productos que no se vendían, la Junta de Arbitrios no recaudaba arbitrios suficientes para atender a su presupuesto.

Las caravanas no vienen, el comercio se halla paralizado, los establecimientos de comercio cierra, y los comerciantes hebreos y moros piensan en emigrar más lejos, más adelante, hacia el lugar de donde viene el daño: a la orilla derecha del Muluya. He ahi el Melilla de hoy; bello bajo su cielo azul; alegre por sus blancas casas; pero que se muere en su efimero esplendor (79).

En mayo de 1909 la cuestión se agrava. Las compañías mineras no se resignan a la situación, sobre todo la Norte Africana, con intereses franceses detrás. El día 6 publicaba El Telegrama del Rif un editorial bajo el título "El suceso del Muluya. Golpe de audacia". En él se daba cuenta de la decisión tomada por la compañía francesa de dar de lado a las autoridades españolas e intentar resolver la cuestión por sus propios medios. Para ello organizó una excursión hacia el Muluya desde la zona francesa, con dirección a las minas de Segangan, acompañando al grupo oficiales franceses. La excursión resultó fallida por la dura oposición de los rifeños, pero alertó al General Marina y al Gobierno, viendo que lo que ellos no hicieran otros lo harían en su lugar (80). "A mí me parecía aquello muy grave", decía Manuel Galván, presente en Melilla (81).

Había que tomar una determinación para acabar con la ya larga situación de asfixia, bloqueo y ruina de Melilla "que se hacía más intolerable porque la prosperidad reciente había hecho olvidar como estado semejante fuera el habitual de aquella plaza". (82).

En la sesión del senado del 12 de mayo, el señor Maura se vio fortalecido por el apoyo encontrado en el grupo liberal, en la persona del General López Domínguez quien, en declaración suscrita por todos los elementos de la Cámara hizo mención al apoyo de los liberales a la "defensa a todo trance del honor de la bandera española, y con la bandera la ocupa- 
ción actual, así como la que proceda, al efecto de defender la plaza de Melilla y sus alrededores" (83).

En sesión del día 22, el liberal don Miguel Villanueva, buen conocedor del problema de Melilla, ciudad a la que había visitado en alguna ocasión, hizo una dramática exposición de la situación de la ciudad, haciendo hincapié en que "lo que hoy se ve allí es la ruina, la miseria y el temor a que todo desaparezca si el Gobierno español tarda mucho en poner remedio" (84).

El Gobierno, pues, se ve compelido a tomar una decisión en algún sentido. Y el único que cabe es el de la intervención armada, siempre contemplada pero siempre evitada por sus consecuencias indeseables. Ya en agosto de 1907, cuando el anterior estado de crisis en Melilla, Maura advertía: "España no puede tomar la ofensiva sin que de allí venga una agresión de tal carácter que el no rechazarla implique una gran vergüenza".

Es decir, lo que se necesitaba era un motivo inmediato, y si el motivo no llegaba espontáneamente había que buscarlo. "Fue necesario que surgiera un serio incidente para que saliéramos de nuestra suicida pasividad", decía Ruiz Albéniz (85).

Una vez asegurados de que Francia y las demás potencias no iban a ser un obstáculo cualquier momento podía ser bueno para encontrarnos con el pretexto. "Nosotros comprendemos sin duda la preocupación de España por ver aseguradas la seguridad y la libertad de las comunicaciones alrededor de Ceuta y de Melilla", decía el Ministro de Asuntos Extranjeros francés, M. Pichon a su diplomático en Madrid (86).

La vía a la intervención estaba libre.

El día 7 de junio se reanudan los trabajos del ferrocarril minero, y el día 9 de julio se produce la agresión que inicia la llamada Campaña del Riff de 1909.

¡Melilla ya no está ahogada! Lo hecho era cuestión de vida o muerte para su existencia. Esta era la razón principal de la guerra" (87). 
1. CANALS, S.: Los sucesos de Lspaña en 1909. Madrid. 1910.

2. Decimos puerto practicable aún cuando en 1909 no había aún tal puerto en la ciudad, puerto que tras no pocas vicisitudes enuró en servicio en 1914. Sin embargo, Melilla reunía las mínimas condiciones precisas para ser base de apoyo a cualquier tipo de intervención armada, pues aún cuando desde un siglo antes había quicnes postulaban por las Chafarinas como punto ideal para una entrada hacia Marruecos era evidente que solamente Melilla podía, aún con graves carencias, atender a las necesidades de un contingente armado to suficientemente mumeroso como para intervenir en el territorio vecino con probabilidades de éxito. Las Chafarinas reunian mejores condiciones para la seguridad de los buques durante nada raros temporales noroeste $y$ noreste que frecuentemente impedian los desembarcos en la rada de Melilla.

3. Ver R.O. de 10-2-1875.

4. SANCHEZ DE VALENZLIIIA, M.: Lina idea sobre el puerto de Melilla. 1904. p.

5. En las circunstancias que entonces se dahan en Melilla, esta clase de comercio no hubiese sido posible por manos de españoles por dos razones fundamentales. Por su particularidad, pues se trataba de un mercado complecamente diferente del habitual en España: y por la manifiesta imposibilidad de acceder al territorio marroquí, puesto de manifiesto en el art". 6" del Tratado por el que se creó una Aduana marroquí en Melilla, y en el que se prohilía expresamente la entrada de los habitantes de Melilla en el Rif. Esta prohibición era obviada por el clemento hebreo al tener libre acceso al territorio vecino, y en todo caso, al disponer de intermediarios de su propia religión en el campo magrebí que actuaban como agentes comerciales de las principales casas comerciales de la ciudad.

6. Ver R. O. de 16-10-1875. Teóricamente los asuntos civiles y las causas criminnles debían verse en los tribunales militares ordinarios de Granada y Ceuta. En la práctica era muy difícil que la autoridad local no interviniese en aquellos asumtos dado el aislamiento de la plaza. Ver R. O. de 10-2-187?.

7. DECHALD, Ed.: Le commerce alger-marocain. Alger. 1906. p. 16.

8. PEZZI, R.: Los presidios menores de Africa y la influencia española en el hif. Madrid. 189.3.
9. Ammario-Cunia Oficial de Marruecos y del Africa Española. 1930, p. 984.

10. DEL BRRLL, G.: España en Marruecos. Intereses generales de España en Marruecos. Intereses generales de España en el valle del Muluyn. en el Rif Oriental y en el Garb, Melilla, 1909.

11. Revista de Geografia Comercial, n" 117. Mayo de 1893.

12. ANDRAIDE, L.: That y Muluya, Memorial de lngenieros, $n^{\prime \prime} \mathrm{XV} .1891$.

13. Revistn de Geogralia Comercial. n" 133 y 134. Sept-()et. 1894.

14. DECHALD, op, cit. p. 18.

15. DI:CHALD, op. cit. p. 19.

16. LLANOS Y AI.CARAZ, A.: Melilla, Madrid. 1894, p. 348, Adolfo Llanos estuvo de corresponsal en Melilla durante la guerra de Margallo como corresponsal de La llustración Nacional.

17. BOADA Y ROMEU, J.: Allende el estrecho, Barcelona. 1895. p. 334: También José Bonda estuvo de corresponsal en la citada campaña.

18. MORAl.lEs, C. de: Datos para la Historia de Melilla, 1908. p. 331.

19. Memoria descriptiva de Melilla y su campo exterior, Melilla. 1894.

20. Revista de Geografía Comercial. n" 133 y 134. sep-oct. 1894.

21. Historia de las Campañas de Marruecos, Servicio Histórico Militar. Tomo I. Madrid. 1947. p. 376.

22. II. Id. p. 460.

23. Id. ld. p. 462.

24. M. Marcet. Revue de Geographie. Cit. pot Boletín de la Real Sociedad Geográfica, 10mo XII. s.a.

25. DECHALD, op. cit. p. 17. Confirmado por Gabriel Delbrel que en aquella época recorría la zona comisionado por la "Sociedad de Geografía Comercial" de París. También por Albert Moulieras. Le Maroc Inconnu, 1895.

26. El Telegrama del Rif, $\mathrm{n}^{\circ} 2241$. DELBREL, G.: España en la Región del Muluya. El trabajo publicado por Delbrel en el desaparecido diario constituye la mejor relación de los hechos acontecidos entre 1900 y 1909 , hechos descritos por un observador excepcional presente en la zona, y cuyo criterio prensamos que debió influir no poco en las autoridades de Melilla, y por su conducto, en el Gobierno español.

27. La mayor parte de estos viajeros pretendía hacer creer aue el principal comercio de Melilla era el contraloundo de armas. 
SEGONZAC, Marqués de: Voyages an Maroc (1899-1901), París, 1903 p. 44 1904

RENE-LECLERC: Le Maroc septentrional.

REZZOUK: Noles sur le Rif, 1906, p. 401.

Creemos que debieron tomar la idea obsesiva del explorador Duveyrier, puesto que cuando este francés estuvo en Melilla en 1899 la venta de armamento a los rifeños estaba autorizada. Poco después fue prohibida.

28. DECHAUD, op. cit. p. 26.

29. DECHAUD, op. cit. p. 2 ?.

30. FAUCOULD, Charles de: Reconnaissance au Maroc, París, 1888. En la edición de Olarieta (1894) p. 248.

31. Plural de "lef": alianza política y militar que vincula a varias tribus formando una especie de federación.

32. LOBERA, C.: Necesidad de un puerto en Melilla considerado desde los puntos de vista politico, militar y comercial, Madrid, 1901, p. 9.

33. LOBERA: op. cit. p. 12.

34. LUQUE, M. y PITA. F.: Estudio sobre el pasado, presente $y$ futuro de nuestras aspiraciones en Marruecos, Madrid, 1902. p. 7. Tanto Luque como Pita fueron oficiales destinados en Melilla por aquellos años. Federico Pita destacó más tarde en el Protectorado marroquí, aunque su actuación no estuvo exenta de polémica.

35. MAURA GAMAZO, G.: La cuestión de Marruecos desde el punto de vista español, Madrid, 1905, p. 267.

36. MAURA GAMAZO op. cit. p. 268.

37. RAMOS ESPINOSA DE LOS MONTEROS, A.: España en Africa, Madrid, 1903, p. 225.

38. El Telegrama del Rif, $\mathrm{n}^{\circ} 373$ (22-3-1903). En el él se da la cifra de 9.310.746, cercana a la de Morales.

39. MORALES, G. de: op. cit. p. 352. Entre los promotores estaba Alexander Baylle, quien más tarde iniciaría el asunto de las minas.

40. ARQUES, E.: Tres sultanes a la porfia de un reino, 1952. Eduardo Maldonado. El Roghi. 1947.

41. BERNARD, A.: Les confins algermarocains, Paris, 1911, p. 316.

42. El 16 de diciembre de $\mathbf{1 9 0 5}$ decía mr. Rouvier a la Cámara francesa que el régimen de la frontera argelina era sólo irıcumbencia de Francia y Marruecos, lo mismo que la zona cercana a Melilla era incumbencia de el segundo país y España. Salvador Canals. op. cit. p. 43.
43. DELBREL, G.: El Telegrama del Rif, $\mathrm{n}^{\text {" }}$ 2241 y ss. mayo de 1909.

44. DELBREL. "Perjuicios que causa Berguent a Melilla". Mismo diario.

45. BESSON, R.: LFinterland algero-marocain, Orán, 1910, p. 13.

46. El Telegrama del Rif. (21-1-1905).

47. FERNANDEZ DE CUEVAS Y DE RAMON, T.: MELILLA. Recuerdos de mi estancia en la plaza africana. Melilla. 1907. Se refiere a los recuerdos conservados de su llegada a la ciudad en 1905 como oficial de la guarnición. Hermano de Fernando, muerto en la Campaña del Rif, cuyo nombre conserva una calle del barrio del Tesorillo.

48. El Telegrama del Rif, $\mathrm{n}^{\circ} 606$. (1-1-1904).

49. LOBERA GIRELA, C.: Memoria sobre la organización y funcionamiento de las Oficinas de Asuntos Arabes de Argelia y Proyecto de Bases para la creación de organismos análogos en las plazas del Norte de Africa, Melilla, 1905, p. 32. Lobera fue comisionado por el General Segura con el fin de aprender - caso raro- de la experiencia francesa en Argelia.

50. BERNARD, op. cit. p. 302. Profesor de la Universidad de Argel, Bernard visitó Melilla en varias ocasiones comisionado por el Gobernador General de Argelia: la primera en 1900, atrayendo su atención el hecho de que "comenzaba a constituirse allí un centro comercial serio muy diferente del vicjo presidio".

51. DIAZ MOREU, E.: La cuestión de Marruecos ante el Senado, Madrid, 1909, p. 30. Díaz Moreu fue el popular capitán del "Conde de Venadito" barco de la Marina de guerra que participó en la guerra de Margallo.

52. Las publicaciones que se refieren a la política de España en el Norte de Africa son numerosísimas $y$ bastantes al alcance de cualquiera. Obviamos el tener que referimos con insistencia a ellas y nos ceñiremos a las que refieren a la cuestión de Melilla expresamente.

53. DIAZ MOREU: op. cit. pp. 30,31 y 37 .

54. DAR EL NIABA: Les origines du "mame espagnol", 1984. p. 21.

55. LOBERA GIRELA, C.: El problema de Melilla, Melilla, 1912, p. 115.

56. Memoria del viaje del señor Ministro de fomento a las nuevas posesiones de Africa, 1910.

57. CABALLERO DE PUCA, E.: Marruecos. 
Politiea e intereses de España en este Imporio, Madrid, 1907. p. 20.

58. REPARAZ, (,. de: Política de Esjoña en Africa, 1907. Ed. de 1924 p. 435.

59. REPARAZ op. cit. p. 43 ?.

60. I.ACUNA AZORIN, J. M": El presidio de Melilla visto por dentro, Valencia. 1907 p. 48. Laguua Azorín era jurídico militar y estuvo destinado en Melilla a su salida de la Arademia en 1904.

61. MUCiLERZA, S.: Melilla comercial. Su porvenir. El Telegrama del Rif. " 1278 (15-3-1906).

62. CABALLERO DE PLGA, op. cit. p. 21.

63. Id. p. 30.

64. León Martín Peinador: Estudios geogríficos, Madrid, 1908, p. 113.

65. El Telegrama del Rif, " 1730 (25-8-1907).

66. CANALS, S., op. cit. p. 47.

67. RUIZ ALBENIZ: El Rif, Madrid. 1912 p. 39. MORALES op. cit. p. 369.

68. LOBERA: El problema de Melilla, p. 115.

69. III Congreso Africanista, diciembre de 1909, Comunicado de la Cámara de Comercio de Melilla.

70. GARCiA PEREZ, A.: Ocho días en Melilla, Barcelona, 1909 , p. 9.

71. GARCIA PEREZ, op. cit. p. 14.

72. LOBERA, C.: El problema rifeño, Melilla, 1909, p. 24.

73. RLIZ ALBENIZ, V.: España en el Rif: Madrid, 1921, pp. 101 y 102.

74. RLIZ ALBENIZ p. 102.
75. RUIZ AI BLENIZ p. 105.

76. RUIZ $\Lambda \mathrm{I}$ Bl:.NIZ p. 106.

77. El Trelegrama del Rif, " $" 1835$ (8-1-1909).

78. Documentos relacionados con la información instruida por la llamada "Comisión de Responsabilidades" acerca del desastre de Annual, Madrid, 1931, p. 419. El General Marina respondía a las pregunas formuladas por el diputado Indalecio Prieto.

79. DEIJ|BREl., G.: España en la región ded Muluya, El Telegrama del Rif, n" 2241 (2-5-1909) y ss.) Este informe llegó a manos del Cobierno, debiendo influir sin duda en la determinación que condujo a los sucesos de julio de 1909.

80. El Telegrama del Rif, n" $22+4$ (6-5-1909).

81. GAI,BAN, M.: España en Africa. La pacificación de Marruecos, Madrid, 1965, p. 32.

82. CANAIS op. cit. p. 59.

83. Jd. p. 61.

84. II. p. 62 .

85. RLIZ AI,BE:VIZ: La campaña del Rif. La verdad de la guerru. Madrid. 1909. p. 33. Ruiz Albéniz fue nombrado médico de la compañía minera española en 1908. Era considerado como uno de los mejores conocedores del problema marroquí y de la intervención española en la zona.

86. Ministère des Affaires etrangères. Documents diplomatiques. Affaires du Maroc: (1908-1910), Paris, 1910, p. 178.

87. BURGLETI: M.: Mis impresiones en la Campaña del Rif de 1909, Barcelona, 1910, p. 31. 